\title{
Regulation of asymmetric cell division in the epidermis
}

Samriddha Ray and Terry Lechler ${ }^{*}$

\begin{abstract}
For proper tissue morphogenesis, cell divisions and cell fate decisions must be tightly and coordinately regulated. One elegant way to accomplish this is to couple them with asymmetric cell divisions. Progenitor cells in the developing epidermis undergo both symmetric and asymmetric cell divisions to balance surface area growth with the generation of differentiated cell layers. Here we review the molecular machinery implicated in controlling asymmetric cell division. In addition, we discuss the ability of epidermal progenitors to choose between symmetric and asymmetric divisions and the key regulatory points that control this decision.
\end{abstract}

\section{Introduction}

Asymmetric cell divisions (ACDs) generate cellular diversity during the development of multi-cellular organisms from a single-celled embryo. The asymmetric division of a progenitor cell generates two daughters with non-identical cell fates, typically one daughter remains a progenitor while the other commits to a defined cell lineage through differentiation [1]. During development and in adult stem cells, ACDs allow for the maintenance of the stem/progenitor cell pool as well as the generation of differentiated cells. While adult stem cells can also undergo symmetric divisions with subsequent differentiation, there is now compelling data that a number of tissue-specific stem/progenitor cells, including those of the neuronal, hematopoietic, muscle and epidermal lineages, undergo ACD [2-6]. This work was made possible and heavily influenced by pioneering studies on ACD in D. melanogaster and C. elegans, which has been reviewed in detail elsewhere $[7,8]$. Recent work has highlighted the advantages of studying ACD in the epidermis, with novel advances in understanding the many levels at which this process is regulated $[5,9,10]$. One crucial determinant of ACD is the axis of spindle orientation and it regulation, which is the major focus of this review.

\section{Discussion}

\section{Epidermal Development}

The epidermis is a multi-layered epithelium. Development of the epidermis from a single layer of epithelial

\footnotetext{
*Correspondence: lechler@cellbio.duke.edu

Department of Cell Biology, Duke University Medical Center, Durham, USA
}

progenitors is termed stratification (Figure 1A). The innermost cell layer, called the basal layer, lies on top of a basement membrane separating it from the underlying dermis. Cells of this layer undergo symmetric divisions to increase surface area through much of development. Starting around embryonic day 13.5 in the mouse, division orientation changes and the majority of divisions occur with the mitotic spindle oriented along the apicalbasal axis of the cell $[5,11]$. These divisions are referred to as asymmetric. Definitive evidence for cell fate asymmetry of these divisions was recently reported [9]. Short-term lineage tracing of dividing progenitor cells revealed that those with spindles perpendicular to the basement membrane gave rise to one basal cell that expressed keratin-14 and one suprabasal cell that expressed keratin 10 [9]. Therefore, there is a clear and direct correlation between spindle orientation and cell fate decisions in the epidermis.

While the connection between spindle orientation and cell fate is incompletely understood, there is evidence for both intrinsic and extrinsic regulation. The basement membrane is a "niche" for progenitors and displacement from that niche, as happens during $A C D$, is likely to play a significant role in cell fate decisions. The integrin family of proteins mediates attachment of the basement membrane to the underlying extracellular matrix (ECM) and integrin-ECM signaling has been implicated in the maintenance of the proliferative state of epidermal basal cells $[12,13]$. Whether physical detachment from the $\mathrm{BM}$ is a necessity to trigger the switch from proliferative to differentiated state needs further investigation. In 
(A)

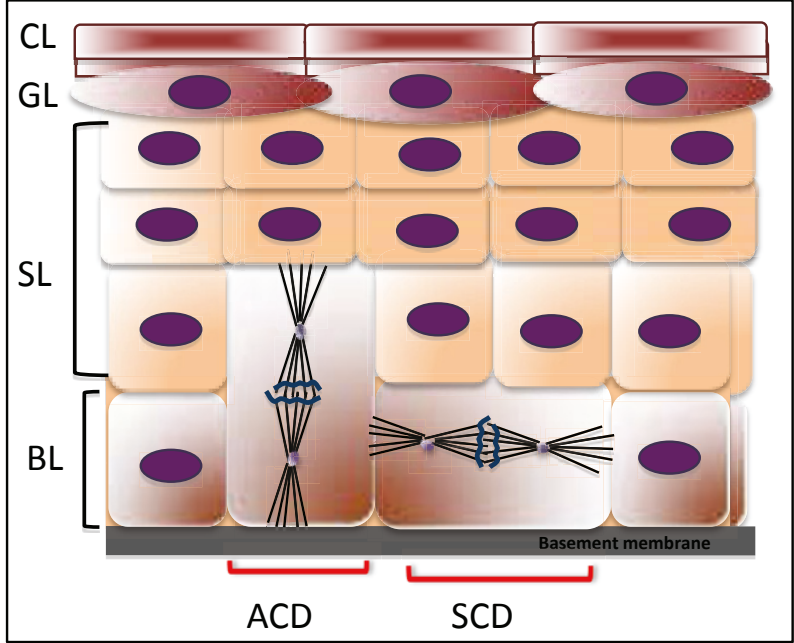

(B)

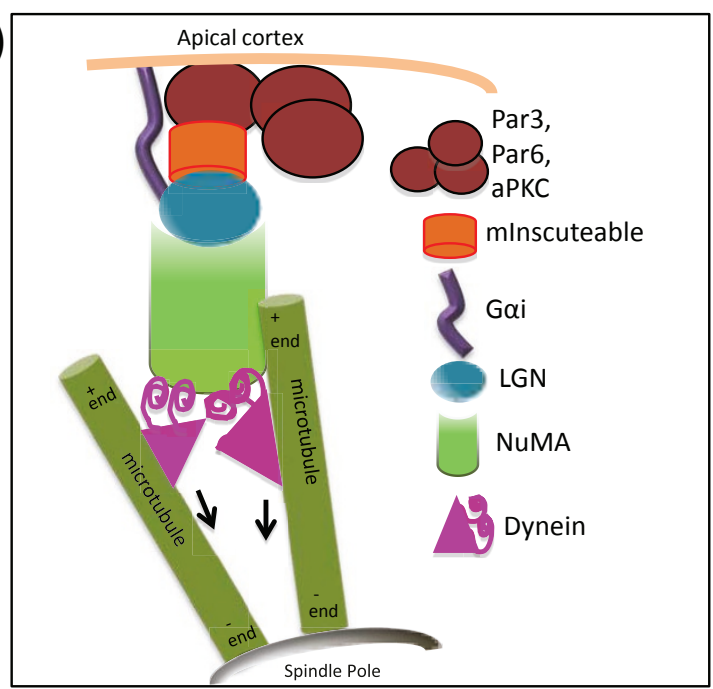

Figure 1 Asymmetric division of epidermal progenitor cells through perpendicular spindle orientation promotes stratification. (A) Epidermis is a multi-layered structure whose inner most layer, the basal layer (BL), contains progenitor cells that can orient their mitotic spindle parallel or perpendicular to the underlying basement membrane (BM) to undergo symmetric (SCD) or asymmetric division (ACD) respectively. Asymmetric division of a basal cell gives rise to a differentiated suprabasal/spinous layer (SL) cell and a proliferative basal cell. Cells of the SL further differentiate and migrate outward to give rise to the granular layer (GL) and the cornified layer (CL). (B) Coupling between the apical Par polarity complex and NuMA in mitosis is proposed to direct apical-basal spindle orientation to drive ACD in the epidermal basal cells.

addition, both EGFR and Notch signaling have been implicated as intrinsic factors that may control the cell fate decision $[10,14,15]$.

\section{Basal Progenitors Have a Choice in Division Orientation} From the onset of stratification until birth, epidermal progenitors balance ACD and SCD (symmetric cell division) to provide a tissue of the right size and thickness. To accomplish this, two extreme models for progenitor organization have been proposed. In one, all cells are committed to either ACD or SCDs. In this case, by balancing the relative proliferation rates of the two types of cells, a tissue could achieve proper development. Alternatively, every cell could have the ability to divide in each orientation. In this case the collective choices that individual cells make would provide the balance. This would suggest that each cell must survey its environment and make a decision each time it divides - asymmetric or symmetric $[16,17]$. Of course, a combination of these could also occur (i.e. a small population of cells committed to a division orientation with others choosing). While an ideal answer to this question would come by imaging repeated cell division cycles in an intact embryo, this has not yet been possible. Instead shortterm lineage tracing studies have been performed which allow the clonal analysis of cells over two divisions cycles where their progeny can be easily classified. Analysis of the results indicated that the majority of basal cells are able to divide both symmetrically and asymmetrically [9].
How does a basal cell regulate its mode of division? As mentioned earlier an essential determinant of asymmetric division is the orientation of the mitotic spindle. Therefore understanding both the machinery that drives spindle reorientation as well as its regulation is paramount.

\section{Molecular Mechanisms Underlying Spindle Reorientation}

Spindle reorientation has been extensively studied in a number of invertebrate model systems and is especially well understood during fly nervous system development $[7,8,18]$. Mechanistic studies of the process in Drosophila neuroblasts have unveiled the existence of a close interplay between polarity complex and microtubuleassociated spindle regulators in regulating the apicobasal spindle orientation. Neuroblast apical-basal polarity is defined by the asymmetric distribution of the Par complex $[19,20]$. Apically localized Par complex, comprised of Par3-Par6-aPKC (atypical protein kinase), serves as a cortical marker for the apico-basal orientation of the mitotic spindle in these cells. Par3 binds and recruits the adaptor proteins Inscuteable and Pins (Partner of Inscuteable) to the apical cortex $[19,20]$. Recruitment of Pins to the apical cortex is further facilitated by its interaction with the Gai subunit of the heterotrimeric G protein complex via its GoLoco motif $[21,22]$. Cortical Pins in turn recruits the Drosophila homolog of mammalian NuMA called MUD [23-25]. Based on its similarity to NuMA and LIN-5 (C.elegans), it is likely that MUD associates with microtubules and the minus end 
directed motor protein, dynein. Thus apically bound NuMA/MUD is hypothesized to act as a cortical anchor for dynein and microtubules which generate a pulling force on the astral microtubules leading to apical-basal spindle orientation $[18,26]$. Similar to the neuroblasts, epidermal progenitor cells exhibit a coupling between the polarity complex and spindle machinery to drive perpendicular spindle orientation in the cells undergoing ACD [5]. Loss of function analysis of LGN and NuMA in epidermal progenitors has demonstrated conserved functions in spindle orientation, failure of which results in impaired differentiation and architecture of the epidermis [8].

Interestingly, in neuroblasts a second spindle orientation pathway has been uncovered that involves interaction of Pins with the tumor suppressor Discs large (Dlg) and microtubule plus-end-directed kinesin heavy chain 73 (khc73) in regulation of ACD $[27,28]$. It remains unknown if epidermal progenitors also have back-up mechanisms to promote $\mathrm{ACD}$ and will require further investigation.

\section{Temporal Regulation of Spindle Orientation}

Because basal cells can divide symmetrically or asymmetrically, this necessitates a choice of division orientation during each mitosis. As a population, the epidermal progenitors must balance SCD and ACD to allow for proper surface area growth at the same time that stratification is occurring. While Drosophila neuroblasts have served as an invaluable model for discovering the molecular machinery involved in ACD, they do not offer insight into this problem. This is because neuroblasts obligately divide asymmetrically - thus the cells do not need to integrate extrinsic signals to decide upon a division orientation. The epidermis, in contrast, offers an ideal system to understand how progenitor cells make this choice. Importantly, asymmetric division is predicted by the spindle orientation, thus allowing an easily visualized readout of this decision. When do cells choose division orientation? Careful analysis in embryos demonstrated that spindle orientation remained random in early mitosis and was stabilized only by late metaphase [9]. This is in contrast to embryonic and larval neuroblasts which pre-pattern their spindle axis even before nuclear envelope breakdown [29]. Because the neuroblasts always divide asymmetrically, this early establishment is a viable option. For epidermal progenitors, the late establishment of spindle orientation by rotation during metaphase may allow them to respond acutely to environmental changes. It is surprising that the very similar machinery in epidermal progenitors and Drosophila neuroblasts achieve the same final result (spindle orientation) through somewhat distinct mechanisms. These data suggest a level of regulation by cell cycle machinery that may include both localization and activation of the ACD apparatus. For example, in Drosophila the NuMA homolog, Mud, is not trapped in the nucleus and therefore does not rely on nuclear envelope breakdown to localize to the apical cell cortex. This may allow its earlier localization and the earlier capture of one of the centrosomes/spindle poles. However, regulation of the activity of the ACD machinery may also occur during mitosis. In C. elegans embryonic development, the timing of spindle forces and displacement are cell-cycle regulated [30]. Similarly, rotation of the mitotic spindle in epidermal progenitors appears to be activated at an ill defined time point. This suggests that the machinery waits, poised for activation. Additional roles for cell cycle machinery in regulating ACD comes from the observation that not only are the levels of mInscuteable and LGN cell-cycle regulated, but so is their localization to the apical cortex $[5,9]$. Whether this is due to modifications that directly affect Par $3 / \mathrm{mIn}$ scuteable interactions is currently under investigation. In Drosophila neuroblasts it is clear that cell cycle regulators, such as Aurora A, act through the polarity complex and aPKC to control the localization of cell fate determinants, though roles in spindle orientation have not been described [31]. Whether this pathway operates in the epidermis has not been addressed.

A fulfilling answer to the question of when a cell decides to divide asymmetrically has not yet been achieved. Based on the spindle orienation studies and expression patterns of $A C D$ machinery [5,9], it is reasonable to speculate that transcriptional control is a key regulatory point during epidermal development.

\section{mInscuteable Expression is Sufficient to Drive ACD}

Extensive research towards understanding the molecular mechanisms of spindle orientation and cell fate determination in Drosophila CNS development led to the identification of Inscuteable as a critical regulator of neuroblast asymmetric division [32]. Inscuteable is specifically expressed in and required for ACD of the neuroblasts but is absent from the symmetrically dividing neuroectoderm. Ectopic expression of the protein in neuroectoderm induced spindle reorientation, similar to what is seen in neuroblasts $[32,33]$. These observations demonstrate both necessity and sufficiency of Inscuteable in ACD. However, if mInscuteable (mInsc) has a similar role in spindle orientation and ACD of epidermal basal cells remained unclear. mInsc is an ideal candidate to control this decision, as it shows a restricted expression pattern and because it links the cortical polarity complex with the mitotic machinery.

To assess whether mInsc was sufficient for inducing spindle reorientation, mice that allowed epidermal-specific and doxycycline-regulated mInscuteable expression 
were generated. This allowed high spatial and temporal control of expression. Short-term (8 hour) induction of mInscuteable expression in the epidermis substantially enhanced the population of asymmetrically dividing cells. This underscored the critical role of mInscuteable in inducing perpendicular spindle orientation in the epidermis. Consistent with previous results, ectopically expressed mInsc maintained its apical localization and co-localized with LGN and the microtubule binding protein NuMA [9]. These observations suggested that mInsc can drive apical localization of other known components of the ACD machinery making it an upstream regulator of epidermal stratification. Importantly, this also increased the fraction of asymmetric cell divisions as determined by a lineage-tracing approach [9].

While mInsc is sufficient to induce ACD, it remains unknown whether it is required for them. Loss of function studies are required to determine whether it is necessary or whether there are redundant mechanisms for either spindle orientation and/or stratification. In further support of mInsc's role in driving spindle reorientation, it undergoes pronounced developmental up regulation at the onset of stratification [9]. Therefore, elucidating the developmental control of mInsc transcription will be essential in understanding stratification.

\section{Robustness in Asymmetric Divisions in the Epidermis}

Although mInsc over-expression generated a marked shift towards asymmetrically dividing cells in short-term inductions, this was not maintained over longer time points. Unexpectedly, prolonged expression of mInsc resulted in a decrease in the percentage of asymmetrically dividing cells [9]. Therefore, the tissue was able to respond to an imbalance in cell division ratios and correct it.

The mechanism underlying this robustness has begun to be understood. It is not due to loss of expression or apical localization of mInsc. Similarly, LGN is still recruited to the apical cell cortex where it co-localizes with mInsc. In these cases a cortical crescent of mInsc/ LGN is clearly uncoupled from the orientation of the mitotic spindle. These results are intriguing because a number of recent papers have suggested that LGN is required for symmetric cell divisions in simple epithelia [34-36]. This data and additional loss of function data argue that LGN is not required for symmetric cell divisions in the epidermis [10]. Therefore, while great progress has been made in identifying the molecular machinery required for $\mathrm{ACD}$ in the epidermis, we still know very little about SCD.

While mInsc/LGN localization are normal after prolonged mInsc expression, the localization of NuMA is notably altered. In all mitotic cells NuMA localizes to the spindle poles. It also localizes to the apical cell cortex (where it colocalizes with mInsc) in asymmetric divisions. This cortical localization was lost after prolonged mInsc expression. Thus the mechanism for robustness of spindle orientation relies on regulated recruitment of NuMA to the apical cell cortex. Evidence that this level of regulation occurs physiologically came from analysis of wild-type embryos. While there is a strong correlation between apical mInsc/LGN and spindle orientation, it is not absolute (i.e. they are uncoupled in wild-type embryos at a low rate). Together these data suggest that mInsc levels dictate a baseline for ACD rate, but that this can be acutely overcome during mitosis by regulating NuMA recruitment (Figure 2). This would allow a cell to quickly respond to extrinsic cues.

\section{Function of p63 in ACD}

p63 is often viewed as a master regulator of stratification due to the profound defects caused by its loss. The ectoderm cells do not commit fully to epidermis and no stratification/differentiation occur [37-40]. p63 was therefore a very good candidate for a transcriptional regulator of mInsc expression. However, examination of mInsc levels in p63 null embryos demonstrated normal expression [9]. Additionally, while late-stage embryos undergo predominantly symmetric cell divisions, embryos at earlier stages exhibit randomized division orientations. The late phenotypes are likely due to decreased proliferation in the epidermal progenitors. As the embryo rapidly grows, the surface ectodermal cells become stretched over the surface and are forced into symmetrical divisions.

If mInsc is expressed, why do these cells not undergo ACD and stratify? Examination of protein localization provided the first clues. While LGN is localized to the apical side of dividing wild type epidermal cells, it is randomized in p63 null embryos. A similar disruption of the apical mInsc/LGN/NuMA complex is also observed in cells lacking an intact basement membrane [5]. In p63 null embryos basement membrane integrity was lost as judged by staining with $\beta 1$-integrin and laminin, suggesting that the effect of p63 could be mediated through disruption of basement membrane. This effect of p63 deletion on the basement membrane was consistent with a previous study reporting its role in maintaining cell adhesion and basement membrane integrity [41]. In particular, that study had identified core basement membrane components as targets of p63. The basement membrane defects result in a loss of cell polarity as evidenced by mislocalization of Par3 and aPKC $\zeta$ and by loss of the activating phosphorylation of aPKC $\zeta$. Thus p63 does not appear to play a direct role in controlling the expression of ACD machinery. However, it remains unclear whether p63 has additional targets that promote polarity or ACD in the epidermis. 


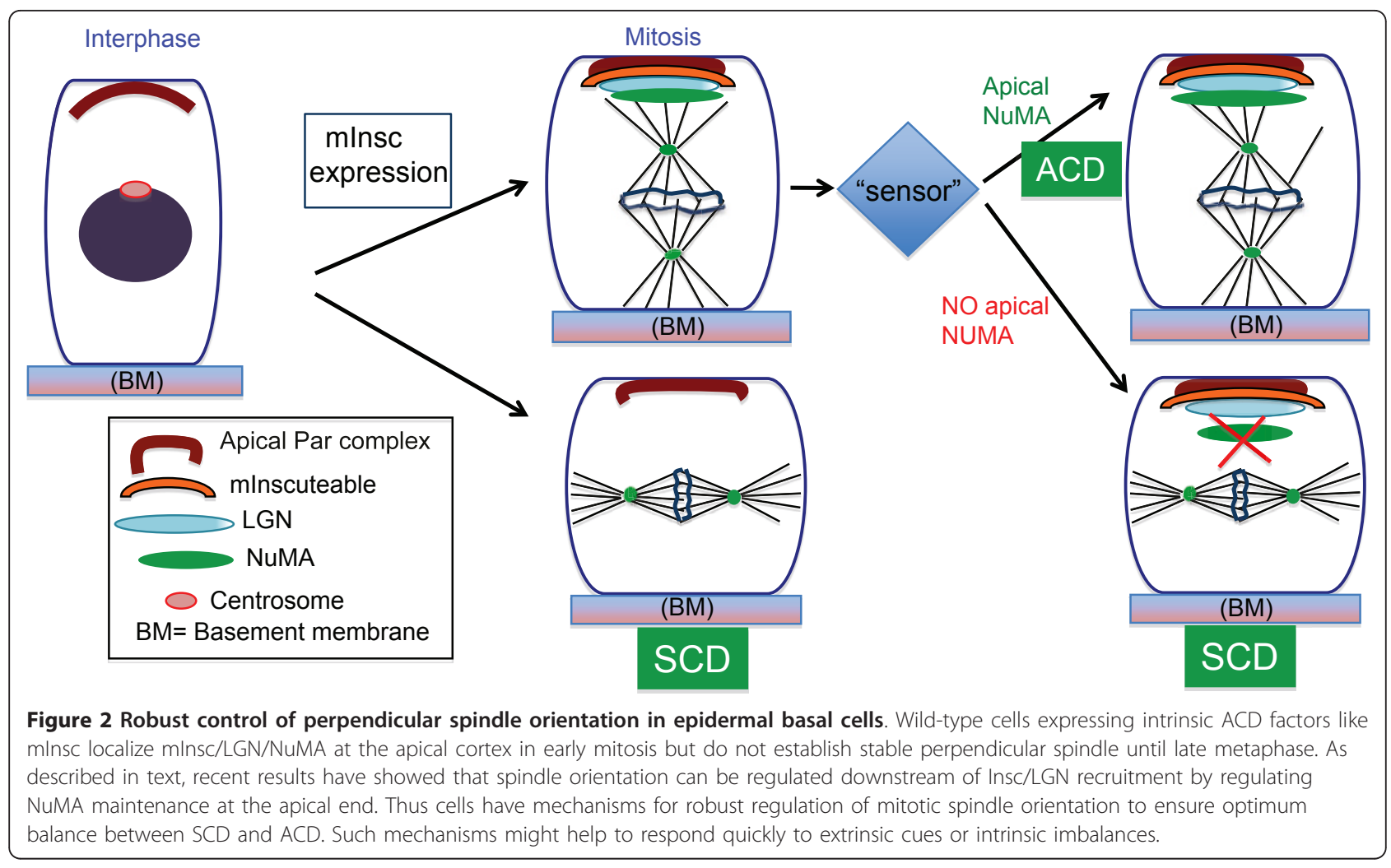

\section{Conclusion}

The multi-layered structure of adult skin is initiated from a single layer during embryonic development. At the root of this process is the ability of basal progenitor cells to undergo ACD to generate one suprabasal cell that is committed to differentiate and another basal cell that maintains its progenitor status. The apical-basal spindle orientation in cells undergoing ACD is facilitated by adaptor proteins mInsc and LGN that allow the coupling between apical polarity and spindle orientation pathways. Consistent with this, expression and localization of mInsc is tightly regulated in a development and cell-cycle dependent manner [5,9]. However, the regulation of Par3 and mInsc interaction through the cell cycle requires further research. Additional work is also required to determine if cell-cell adhesion structures are also involved in the correct localization of ACD regulators. Previous work has implicated adherens junctions in the cortical localization of LGN and Par3, and in spindle orientation [5,42]. How adherens junction proteins control cell polarity and spindle orientation is poorly understood. A clear understanding of the roles of polarity and adhesion components in regulation of ACD will be useful to understand how the machinery responds to injuries that disrupt intercellular adhesion and structural integrity.

Furthermore, the current study by Poulson and Lechler revealed that the mechanism of $A C D$ is far from simple and involves regulation at multiple levels [9]. The observations upon prolonged expression of mInsc suggested that 1) apical Insc/LGN could be uncoupled from spindle orientation, 2) NuMA maintenance at the apical cortex is a crucial regulatory point for perpendicular spindle orientation during ACD and 3) basal cells have mechanism/s that sense and respond to imbalances in division orientation. The molecular nature of such a "sensor" requires further investigation but one intriguing candidate is tension in the basal layer of cells.

The role and regulation of spindle orientation during ACD is only beginning to be understood in vertebrates. Deregulation of spindle orientation not only generates developmental defects in epidermal and neuronal cells, but has also been implicated in tumorigenesis in the human gut epithelium, further underscoring its importance [43]. Thorough understanding of the ACD machinery in diverse cell types will be important to fully appreciate their role in normal development and during pathology.

\section{Acknowledgements and Funding}

The authors wish to thank members of the Lechler lab for stimulating discussions. The lab is supported by grants from the NIH-NIAMS, the Kimmel Foundation, the March of Dimes and the Duke Cancer Center.

Authors' contributions

SR and TL wrote and approved the manuscript. 


\section{Competing interests}

The authors declare that they have no competing interests.

Received: 1 March 2011 Accepted: 6 June 2011 Published: 6 June 2011

\section{References}

1. Morrison SJ, Kimble J: Asymmetric and symmetric stem-cell divisions in development and cancer. Nature 2006, 441:1068-1074.

2. Kuang S, Kuroda K, LeGrand F, Rudnicki MA: Asymmetric self-renewal land commitment of satellite stem cells in muscle. Cell 2007, 129:999-1010.

3. Yamashita YM, Yuan $\mathrm{H}$, Cheng J, Hunt AJ: Polarity in stem cell division: asymmetric stem cell division in tissue homeostasis. Cold Spring Harb Perspect Biol 2010, 2:a001313.

4. Wu M, Kwon HY, Rattis F, Blum J, Zhao C, Ashkenazi R, Jackson TL, Gaiano N, Oliver T, Reya T: Imaging hematopoietic precursor division in real time. Cell Stem Cell 2007, 1:541 554.

5. Lechler T, Fuchs E: Asymmetric cell divisions promote stratification and differentiation of mammalian skin. Nature 2005, 437:275-280.

6. Zhong W, Chia W: Neurogenesis and asymmetric cell division. Curr Opin Neurobiol 2008, 18:4-11.

7. Gonczy P: Mechanisms of asymmetric cell division: flies and worms pave the way. Nat Rev Mol Cell Biol 2008, 9:355-366.

8. Knoblich JA: Asymmetric cell division: recent developments and their implications for tumour biology. Nat Rev Mol Cell Biol 2010, 11:849-860.

9. Poulson ND, Lechler T: Robust control of mitotic spindle orientation in the developing epidermis. J Cell Biol 2010, 191:915-922.

10. Williams SE, Beronja S, Pasolli HA, Fuchs E: Asymmetric cell divisions promote Notch-dependent epidermal differentiation. Nature 2011, 470:353-358.

11. Smart IH: Variation in the plane of cell cleavage during the process of stratification in the mouse epidermis. Br J Dermatol 1970, 82:276-282.

12. Fuchs $E$, Raghavan $\mathrm{S}$ : Getting under the skin of epidermal morphogenesis. Nat Rev Genet 2002, 3:199-209.

13. Watt FM: Role of integrins in regulating epidermal adhesion, growth and differentiation. EMBO J 2002, 21:3919-3926.

14. Blanpain C, Lowry WE, Pasolli HA, Fuchs E: Canonical notch signaling functions as a commitment switch in the epidermal lineage. Genes Dev 2006, 20:3022-3035.

15. Le Roy H, Zuliani T, Wolowczuk I, Faivre N, Jouy N, Masselot B, Kerkaert JP, Formstecher P, Polakowska R: Asymmetric distribution of epidermal growth factor receptor directs the fate of normal and cancer keratinocytes in vitro. Stem Cells Dev 2010, 19:209-220.

16. Hall PA, Watt FM: Stem cells: the generation and maintenance of cellular diversity. Development 1989, 106:619-633.

17. Watt FM, Hogan BL: Out of Eden: stem cells and their niches. Science 2000, 287:1427-1430

18. Knoblich JA: Mechanisms of asymmetric stem cell division. Cell 2008, 132:583-597.

19. Wodarz A, Ramrath A, Kuchinke U, Knust E: Bazooka provides an apical cue for Inscuteable localization in Drosophila neuroblasts. Nature 1999, 402:544-547.

20. Schober M, Schaefer M, Knoblich JA: Bazooka recruits Inscuteable to orient asymmetric cell divisions in Drosophila neuroblasts. Nature 1999, 402:548-551

21. Yu F, Wang H, Qian H, Kaushik R, Bownes M, Yang X, Chia W: Locomotion defects, together with Pins, regulates heterotrimeric G-protein signaling during Drosophila neuroblast asymmetric divisions. Genes Dev 2005, 19:1341-1353.

22. Yu F, Ong $C T$, Chia $W$, Yang $X$ : Membrane targeting and asymmetric localization of Drosophila partner of inscuteable are discrete steps controlled by distinct regions of the protein. Mol Cell Biol 2002, 22:4230-4240.

23. Izumi Y, Ohta N, Hisata K, Raabe T, Matsuzaki F: Drosophila Pins-binding protein Mud regulates spindle-polarity coupling and centrosome organization. Nat Cell Biol 2006, 8:586-593.

24. Siller KH, Cabernard C, Doe CQ: The NuMA-related Mud protein binds Pins and regulates spindle orientation in Drosophila neuroblasts. Nat Cell Biol 2006, 8:594-600.

25. Bowman SK, Neumuller RA, Novatchkova M, Du Q, Knoblich JA: The Drosophila NuMA Homolog Mud regulates spindle orientation in asymmetric cell division. Dev Cell 2006, 10:731-742.
26. Siller $\mathrm{KH}$, Doe CQ: Spindle orientation during asymmetric cell division. Nat Cell Biol 2009, 11:365-374.

27. Johnston CA, Hirono K, Prehoda KE, Doe CQ: Identification of an Aurora-A/ PinsLINKER/Dlg spindle orientation pathway using induced cell polarity in S2 cells. Cell 2009, 138:1150-1163.

28. Siegrist SE, Doe CQ: Microtubule-induced Pins/Galphai cortical polarity in Drosophila neuroblasts. Cell 2005, 123:1323-1335.

29. Januschke J, Gonzalez C: The interphase microtubule aster is a determinant of asymmetric division orientation in Drosophila neuroblasts. J Cell Biol 2010, 188:693-706.

30. McCarthy Campbell EK, Werts AD, Goldstein B: A cell cycle timer for asymmetric spindle positioning. PLOS Biol 2009, 7:e1000088.

31. Wirtz-Peitz F, Nishimura T, Knoblich JA: Linking cell cycle to asymmetric division: Aurora-A phosphorylates the Par complex to regulate Numb localization. Cell 2008, 135:161-173.

32. Kraut $R$, Chia $W$, Jan $L Y$, Jan $Y N$, Knoblich JA: Role of inscuteable in orienting asymmetric cell divisions in Drosophila. Nature 1996, 383:50-55

33. Doe CQ: Spindle orientation and asymmetric localization in Drosophila: both inscuteable? Cell 1996, 86:695-697.

34. Hao Y, Du Q, Chen X, Zheng Z, Balsbaugh JL, Maitra S, Shabanowitz J, Hunt DF, Macara IG: Par3 controls epithelial spindle orientation by aPKCmediated phosphorylation of apical Pins. Curr Biol 2010, 20:1809-1818.

35. Zheng Z, Zhu H, Wan Q, Liu J, Xiao Z, Siderovski DP, Du Q: LGN regulates mitotic spindle orientation during epithelial morphogenesis. J Cell Biol 2010, 189:275-288

36. Rodriguez-Fraticelli AE, Vergarajauregui S, Eastburn DJ, Datta A, Alonso MA, Mostov K, Martin-Belmonte F: The Cdc42 GEF Intersectin 2 controls mitotic spindle orientation to form the lumen during epithelial morphogenesis. J Cell Biol 2010, 189:725-738.

37. Koster Ml, Dai D, Marinari B, Sano Y, Costanzo A, Karin M, Roop DR: p63 induces key target genes required for epidermal morphogenesis. Proc Natl Acad Sci USA 2007, 104:3255-3260.

38. Koster MI, Dai D, Roop DR: Conflicting roles for p63 in skin development and carcinogenesis. Cell Cycle 2007, 6:269-273.

39. Mills AA, Zheng B, Wang XJ, Vogel H, Roop DR, Bradley A: p63 is a p53 homologue required for limb and epidermal morphogenesis. Nature 1999, 398:708-713.

40. Yang A, Schweitzer R, Sun D, Kaghad M, Walker N, Bronson RT, Tabin C, Sharpe A, Caput D, Crum C, McKeon F: p63 is essential for regenerative proliferation in limb, craniofacial and epithelial development. Nature 1999, 398:714-718

41. Carroll DK, Carroll JS, Leong CO, Cheng F, Brown M, Mills AA, Brugge JS, Ellisen LW: p63 regulates an adhesion programme and cell survival in epithelial cells. Nat Cell Biol 2006, 8:551-561.

42. Gladden AB, Hebert AM, Schneeberger EE, McClatchey Al: The NF2 tumor suppressor, Merlin, regulates epidermal development through the establishment of a junctional polarity complex. Dev Cell 2010, 19:727-739.

43. Graham TA, Jawad N, Wright NA: Spindles losing their bearings: does disruption of orientation in stem cells predict the onset of cancer? Bioessays 2010, 32:468-472.

doi:10.1186/1747-1028-6-12

Cite this article as: Ray and Lechler: Regulation of asymmetric cell division in the epidermis. Cell Division 2011 6:12.

\section{Submit your next manuscript to BioMed Central and take full advantage of:}

- Convenient online submission

- Thorough peer review

- No space constraints or color figure charges

- Immediate publication on acceptance

- Inclusion in PubMed, CAS, Scopus and Google Scholar

- Research which is freely available for redistribution 